$10-2020$

\title{
Measurement of anticipated stigma: A barrier to family planning use among married youth
}

Evidence Project

Follow this and additional works at: https://knowledgecommons.popcouncil.org/departments_sbsr-rh How does access to this work benefit you? Let us know!

\section{Recommended Citation}

Evidence Project. 2020. "Measurement of anticipated stigma: A barrier to family planning use among married youth." Washington, DC: Population Council, The Evidence Project. 


\section{Measurement of anticipated stigma: $\mathbb{A}$ barrier to family planning use among married youth}

\section{TOOL}

\section{WHY MEASURE ANTICIPATED STIGMA?}

Globally, 33 million female youths aged 15-24 have an unmet need for voluntary family planning (FP)-they are able to get pregnant, sexually active, and do not want to become pregnant but are not using a contraceptive method. ${ }^{1}$ Many married female youths face unique barriers including social pressure to have a child early in marriage as well as social isolation and restricted mobility. Anticipated stigma, the belief that others will discriminate against oneself, is a known barrier to seeking certain health services. However, anticipated stigma has yet to be assessed as a barrier in the context of married youth's need for voluntary FP. The Evidence Project undertook a study to assess youth's awareness and perceptions of available health services and their service utilization behaviors and preferences. ${ }^{2}$ As part of this study, the Evidence Project validated an anticipated stigma index and explored its relationship with unmet need for FP among married female youth in Ethiopia. $^{3}$

A cross-sectional household survey was conducted among 3,611 male and female youth aged 12 to 24 years in Ethiopia. To measure the association between anticipated stig-

\section{KEY MESSAGES}

Anticipated stigma among married youth is associated with an unmet need for FP in Ethiopia.

The Evidence Project validated a 5-item anticipated stigma index that is associated with higher levels of unmet need.

Future research should test this measure in other countries and among different adolescent groups.

ma and unmet need for FP, the sample was limited to 371 15- to 24-year-old married female youth with a demand for FP (defined as either currently using FP-having a met need-or having an unmet need). Respondents were asked a variety of attitudinal questions about how they would feel if they were planning to seek voluntary FP services next week (Table 1). Principal components factor analysis was used to reduce the items. Two factors emerged: one on anticipated stigma, and one on the desire to be accompanied when seeking services (see blue items in Table 1).

TABLE 1. FACTOR LOADINGS FOR ANTICIPATED STIGMA AND DESIRE TO BE ACCOMPANIED INDICES (N=371)

\begin{tabular}{|c|c|c|c|}
\hline $\begin{array}{l}\text { SUPPOSE THAT YOU WERE PLANNING TO GET SERVICES RELATED TO FAMILY PLANNING NEXT WEEK. PLEASE } \\
\text { KEEP THIS SCENARIO IN MIND AND TELL ME IF YOU: STRONGLY DISAGREE, DISAGREE, AGREE OR STRONGLY } \\
\text { AGREE WITH THE FOLLOWING STATEMENTS. }\end{array}$ & $\begin{array}{l}\% \text { STRONGLY } \\
\text { AGREE/ } \\
\text { AGREE }\end{array}$ & $\begin{array}{l}\text { FACTOR 1: } \\
\text { ANTICIPATED } \\
\text { STIGMA }\end{array}$ & $\begin{array}{c}\text { FACTOR 2: } \\
\text { ACCOMPANY }\end{array}$ \\
\hline a) I would need more information about FP services & 97.6 & -0.072 & 0.270 \\
\hline b) I would know where to go to get FP services & 99.2 & 0.104 & 0.143 \\
\hline c) I would want my boyfriend/partner/husband to come with me to get FP & 77.1 & 0.009 & 0.554 \\
\hline d) I would feel embarrassed about wanting more information about FP services & 8.9 & 0.563 & -0.091 \\
\hline e) I would want a female family member to come with me to get family FP & 69.5 & 0.058 & 0.781 \\
\hline f) I would be afraid of being seen by someone I knew at the facility & 11.9 & 0.662 & -0.012 \\
\hline g) I would be worried about what my parents would say if they found out that I needed FP services & 14.3 & 0.627 & 0.097 \\
\hline h) My boyfriend/partner/husband would support me in my decision to get FP & 88.1 & -0.149 & 0.265 \\
\hline i) I would want a female friend to come with me to get FP & 70.9 & 0.029 & 0.788 \\
\hline j) I would be worried that religious leaders in my community would not support me & 31.5 & 0.188 & 0.029 \\
\hline k) I would be worried about what people in my community would say about me if they found out I needed FP & 10.0 & 0.698 & 0.045 \\
\hline I) I would trust that FP providers will keep my personal and health information confidential & 91.9 & -0.206 & 0.263 \\
\hline m) I would feel embarrassed talking to a provider about FP & 7.6 & 0.597 & 0.005 \\
\hline n) I would be worried that the cost of the FP services would be too high & 13.8 & 0.449 & 0.122 \\
\hline Cronbach's $\alpha$ & & 0.66 & 0.53 \\
\hline
\end{tabular}


The second factor, desire to be accompanied, was explored in the analysis but was excluded from the results because the three items had a low Cronbach's $\alpha$ score and lack of significant associations. Further research could explore whether this factor is associated with unmet need for FP among youth in other settings.

The anticipated stigma index was formed using a composite score from zero to five for the five items and was dichotomized into no agreement with any item and agreement with at least one item (Figure 1). A multivariate logistic regression model was used to assess the relationship of anticipated stigma, on unmet need for FP.

Thirty percent of respondents agreed with at least one item of the anticipated stigma index (Figure 1). These respondents were nearly twice as likely $(A O R=1.97)$ to have an unmet need for FP (Table 2) compared to those who reported no anticipated stigma, after adjusting for other barriers to use.

\section{FIGURE 1. AGREEMENT WITH ANTICIPATED STIGMA STATEMENTS BY 15- TO 24-YEAR-OLD MARRIED FEMALE YOUTH}

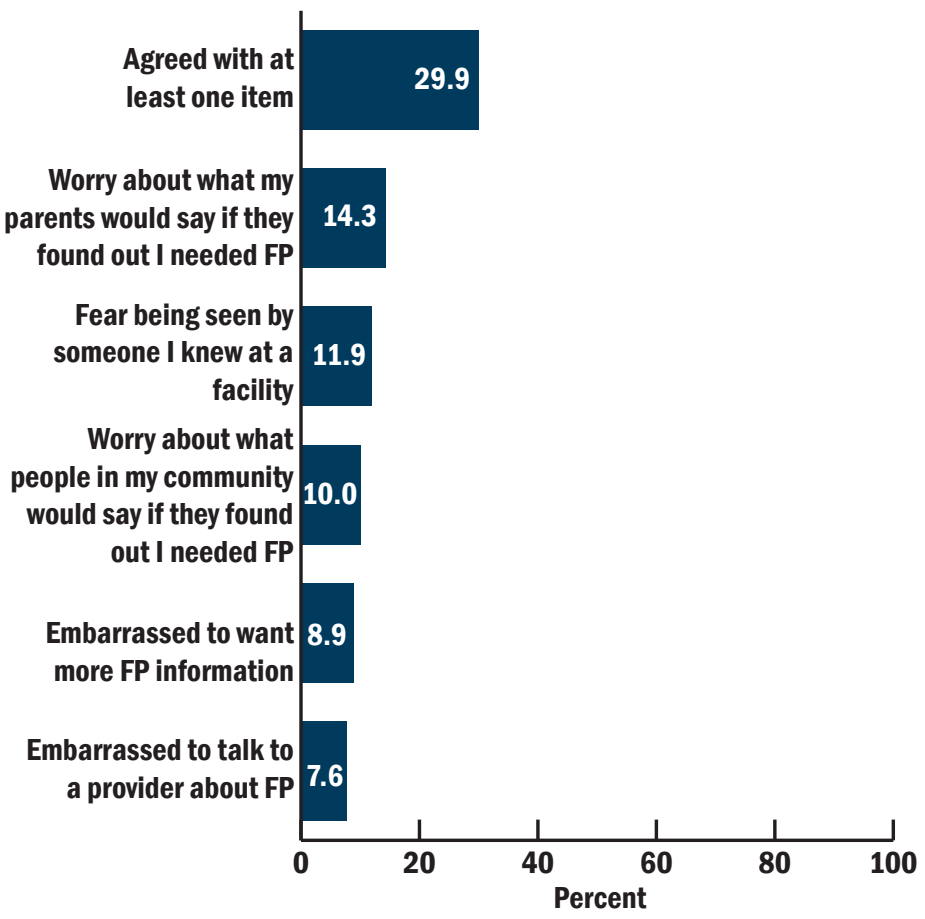

TABLE 2. UNADJUSTED AND ADJUSTED ODDS RATIOS (OR) OF UNMET NEED FOR FP AND ANTICIPATED STIGMA

\begin{tabular}{|lcccc|}
\hline ANTICIPATED & UNADJUSTED & & ADJUSTED & $95 \%$ \\
STIGMA INDEX & OR & $95 \% \mathrm{Cl}$ & OR $^{\dagger}$ & $\mathrm{Cl}$ \\
\hline No stigma & Ref. & & Ref. \\
\hline Stigma on $1-5$ items & $1.86 * *$ & $(1.19-2.91)$ & $1.97^{*}$ & $(1.16-3.36)$ \\
\hline
\end{tabular}

${ }^{\dagger}$ Adjusted for region, religion, education, age, parity, age at marriage, spends time at mosque/church, has own savings, involvement in decisions, and distance to a youth friendly service site.

"p $\leq 0.05 ; " * 0 \leq 0.01 ; * * * 0.001$

Based on these results, efforts to increase access to voluntary FP services should address anticipated stigma. Despite the social barriers that youth face when seeking $\mathrm{FP} / \mathrm{RH}$ services, 56 percent of married youth with a need for FP in this study had met this need and were using contraception. Further research to understand how youth overcome barriers to accessing FP would be beneficial in designing programs for those who experience anticipated stigma and have yet to overcome barriers to access. Findings from this study demonstrate that the anticipated stigma index is a valid and reliable measure and should be replicated and tested in other contexts and among other populations outside of Ethiopia.

\section{REFERENCES}

${ }^{1}$ MacQuarrie, KLD. 2014. “Unmet need for family planning among young women: levels and trends," DHS Comparative Reports No. 34. ICF International, Rockville, MD.

2Jain, A., H. Ismail, E. Tobey, and A. Erulkar. 2017. “Understanding adolescent and youth sexual and reproductive health-seeking behaviors in Ethiopia: implications for youth friendly service programming." Washington, DC: Population Council, The Evidence Project.

3Jain, A., H. Ismail, E. Tobey, and A. Erulkar. 2019. "Stigma as a barrier to family planning use among married youth in Ethiopia," Journal of Biosocial Science 51(4): 505-519. doi: 10.1017/ S0021932018000305

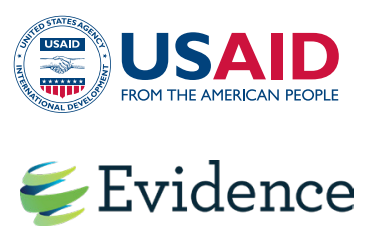

The Evidence Project uses implementation science-the strategic generation, translation, and use of evidence-to strengthen and scale up family planning and reproductive health programs to reduce unintended pregnancies worldwide. The Evidence Project is led by the Population Council.

(c) 2020. The Population Council, Inc.
The Evidence Project is made possible by the generous support of the American people through the United States Agency for International Development (USAID) under the terms of cooperative agreement no. AID-OAA-A-13-00087. The contents of this document are the sole responsibility of the Evidence Project and Population Council and do not necessarily reflect the views of USAID or the United States Government.

For more information, go to evidenceproject.popcouncil.org or send an e-mail to evidenceproject@popcouncil.org 